\title{
Travessias: romance e experiência em Mia Couto e Guimarães Rosa
}

\section{Crossings: novel and experience in Mia Couto and Guimarães Rosa}

\section{Naira Almeida Nascimento}

Resumo: A aproximação entre a escrita do consagrado autor moçambicano Mia Couto (1955- ) e a do brasileiro Guimarães Rosa (1908-1967), já mereceu a consideração de numerosos estudos críticos. O presente artigo volta-se para a produção romanesca de ambos, procurando evidenciar uma outra questão, em geral menos evidenciada pela crítica que aborda a interação entre eles: a figura do mediador. Objetiva-se averiguar de que forma a inserção de uma figura mediadora no plano literário, localizada entre as culturas tradicionais rurais e as culturas letradas urbanas, tenta colmatar problemas da tradução linguística, da verossimilhança ficcional no contexto dessas obras e, ainda assim, perspectiva uma espécie de alter-ego narrativo.

Palavras-chave: Mia Couto, Guimarães Rosa, literatura comparada, alteridade.

\begin{abstract}
The similarities between the writing of the renowned Mozambican author Mia Couto (1955- ) and the Brazilian Guimarães Rosa (1908-1967) have merited further consideration of numerous critical studies. This study is focused on their novelistic production, seeking to highlight another issue generally relegated by critics about the interaction between them: a mediating figure. The purpose is to investigate how the inclusion of a mediating figure in the literary plane, located between the traditional rural cultures and urban literate ones, attempts to bridge the linguistic translation problems, the fictional verisimilitude in the context of these works, and yet, a sort of alter-ego narrative perspective.
\end{abstract}

Keywords: Mia Couto, Guimarães Rosa, comparative literature, otherness.

Professora Adjunta de Literatura da UTPFR, Campus Curitiba, com mestrado e doutorado em Estudos Literários pela UFPR. 
aproximação entre a escrita do consagrado autor moçambicano Mia Couto e a do brasileiro Guimarães Rosa já mereceu a consideração de variados estudos críticos que assinalam, sobretudo, o trabalho linguístico original de ambos, como também, e de certa forma como causa do primeiro aspecto, o resgate de tradições culturais de seus países, normalmente conotadas com a oralidade.

São sobejamente conhecidas as declarações de Mia Couto ao reconhecer o profundo impacto proporcionado pela leitura de Guimarães Rosa nos desdobramentos do seu projeto literário, seja como opção estética, seja no plano político da linguagem. $O$ moçambicano confessa, contudo, que essa referência veio bem tardiamente, muito tempo após o contato com os escritos do angolano Luandino Vieira (1935- ) ), esse sim, que teria, segundo ele, conhecido na fonte o estilo rosiano. Não por acaso, a produção dos três escritores é normalmente estudada pelo prisma linguístico, enquanto exemplos de rupturas acentuadas da língua portuguesa no seu formato padrão. Assim, enquanto nas páginas de Rosa exalta-se o país mítico e ao mesmo tempo histórico das Gerais, as obras de Luandino Vieira e de Mia Couto expressam, respectivamente, o mundo dos musseques da angolana Luanda e a imensidão das savanas moçambicanas, espaços que literariamente escapam aos domínios de uma cartografia física. A descoberta da obra de Guimarães seria para Mia Couto como que o descortinar de uma nova forma de interpretar o mundo:

Quando o li pela primeira vez experimentei uma sensação que já tinha sentido quando escutava os contadores de histórias da infância. Perante o texto, eu não lia simplesmente: eu ouvia vozes da infância. Os livros de João Guimarães Rosa atiravam-me para fora da escrita como se, de repente, eu me tivesse convertido num analfabeto selectivo. Para entrar naqueles textos eu devia fazer uso de um outro acto que não é "ler", mas que pede um verbo que ainda não tem nome.

Mais que a invenção de palavras, o que me tocou foi a emergência de uma poesia que me fazia sair do mundo. Aquela era uma linguagem em estado de transe, que entrava em transe como os médiuns das cerimónias mágicas e religiosas. Havia como que uma embriaguez profunda que autorizava a que outras linguagens tomassem posse daquela linguagem. Exactamente como o dançarino da minha terra que não se limita a dançar. Ele prepara a possessão pelos espíritos. Ele cria o momento religioso em que emigra o seu próprio corpo. (COUTO, 2011, p. 118). 
Tal criação, da esfera do artístico, não esconde todavia uma imensa simpatia de seus autores pelas comunidades e pelas tradições que habitam esses espaços. Revelam eles não apenas a convocação de personagens à margem do processo "civilizacional", mas também uma necessidade de servir de medium para as histórias escutadas e de encenar os "pequenos grandes" dramas de seus personagens. Isso tudo, através da superação do incômodo fantasma do discurso paternalista, que quase sempre rondou as representações desse tipo.

$E$, por essa mesma razão, a de superar as dicotomias que acercam as narrativas sobre a alteridade, é que elas pressupõem novas tomadas ficcionais. Não se trata de mascarar ou de simplesmente teatralizar o encontro com o outro, mas também de evidenciar as tensões que perpassam tal diálogo. Portanto, ler a literatura coutiana como metáfora pura e simples do abraço irrestrito com as vozes das culturas tradicionais pode redundar num empobrecimento do artefato literário. Isso porque partimos do entendimento de que tais escritos, em lugar da inversão pura e simples dos lugares ocupados historicamente pelas culturas letradas e pelas culturas orais, problematizam as situações de parte a parte. $\mathrm{Ou}$ seja, apesar de comportarem uma dose de utopia, eles não abdicam da reflexão proporcionada pelo enfrentamento de tensões latentes, sejam elas resultantes do processo colonial ou de conflitos mais recentes.

A proposta do presente trabalho é justamente investigar a figura do mediador, presente tanto no romance Grande sertão, veredas, como em grande parte dos romances de Mia Couto, enquanto uma instância investida do poder de encenar as tensões percebidas entre o lado de cá e o lado de lá, ou seja, entre os espaços da cultura letrada e da cultura oral, ou ainda entre as dicotomias e os desdobramenteos que daí advêm.

Valemo-nos, primeiramente, da indagação: por que Riobaldo, protagonista de Grande sertão, veredas, narra seu drama íntimo a um viajante, que, por sua vez, vai narrar a história do jagunço que se tornou barranqueiro? E quem é esse outro, de quem não conhecemos o nome, a origem ou o destino, mas, segundo indica o relato, trata-se de indivíduo letrado e com ares urbanos?² Conforme argumenta Kathrin Rosenfield em relação à inserção do intelocutor:

2 "Mas não diga o senhor, asisado e instruído, que acredita na pessoa dele?!" (ROSA, 2006, p. 10). "Mas o senhor é homem sobrevindo, sensato, fiel como papel, o senhor me ouve, pensa e repensa, e rediz, então me ajuda" (ROSA, 2006, p. 100). 
O silêncio não é ausência, mas presença negativa: é como um "negativo" da presença falante de Riobaldo, de forma que ele e o senhor (como funções do discurso) correspondem-se na ordem da simetria invertida. À fala de Riobaldo "responde" o silêncio que pontua e inflexiona essa fala. [...]

Falar consigo pressupõe, no mínimo, uma distância em relação a si, o espaço ou o intervalo do "ser-outro", que é reconhecimento da alteridade. Daí a necessidade da dupla leitura dessa fórmula: o estranho vem a significar o reconhecimento da distância que separa o sujeito (a pessoa no sentido de persona, máscara, identidade escolhida) do seu ser-imediato, da espontaneidade dos seus sentimentos e paixões. (ROSENFIELD, 2006, p. 363).

De forma análoga, fica a questão: que papel desempenham Muidinga, Izidine Naíta, o tradutor de Tinzagara e Massimo Risi, Mariano Malta, Mwadia Malunga, Sidónio Rosa, Deolinda, Marta e Mwanito, Arcanjo Baleiro, Gustavo Regalo e Mariamar, respectivamente personagens de Terra sonâmbula, A varanda de Frangipani, $O$ último voo do flamingo, Um rio chamado tempo, uma casa chamada terra, O outro pé da sereia, Venenos de Deus, remédios do Diabo, Antes de nascer o mundo e $A$ confissão da leoa, ${ }^{3}$ senão a tentativa ficcional de traduzir e interagir com expressões distintas de mundo?

Como se pode ver, o estudo comparativo das obras de G. Rosa e de Mia Couto permite ainda algumas aproximações não aprofundadas pela crítica especializada. Focadas normalmente nos aspectos linguísticos ou nas evidências das tradições oralizantes em tais obras, uma boa parte dos estudos opta por privilegiar a dicotomia construída entre o caráter realista e animista, com foco privilegiado no segundo elemento, conotado ipsis litteris com as culturas africanas em geral. Algumas abordagens, contudo, como a seguida por Rita Chaves, em especial no ensaio "Guimarães Rosa: do sertão às savanas", escapam a essa estereotipia ao assinalar o caráter móvel e híbrido dessa produção:

A idéia, e correta, diga-se de passagem, da existência de uma variante da língua portuguesa em Moçambique faz levantar no leitor a suspeita de que a linguagem utilizada por Mia corresponde ao modo de falar dos moçambicanos, como se

3 Todos romances editados no Brasil, pela Companhia das Letras, respectivamente, em 1992, 1996, 2000, 2002, 2006, 2008, 2009 e 2012. 
tivéssemos ali um reflexo direto do uso do idioma; porém, remoldar a língua não significa propriamente para Mia Couto incorporar a fala dos habitantes cujo contato com o português não resultou num domínio efetivo do idioma. (CHAVES, 2008, p. 141).

\section{A tradição regionalista e a inclusão do "outro"}

A tradição regionalista brasileira sempre se defrontou com um problema de ordem literária, mas que também reflete as contradições ideológicas do nosso processo social: como representar a figura do outro, sobretudo daquele que, diante do meio urbano que se torna preponderante em meados do século XX, ocupa a fatia rural e que vai ganhando contornos de singularidade pela perspectiva civilizacional?

Se o regionalismo romântico optou por uma ótica integradora, ou seja, a reivindicação de um país continental com uma multiplicidade regional, o discurso que vai tomando forma desde o naturalismo de Franklin Távora, assume a coloração de uma disputa de ordem, sobretudo política, na defesa dos rincões brasileiros desprestigiados pelo poder hegemônico fundado no sudeste do país. A tônica persiste e com maior rigor com a literatura finissecular e mais tarde, passado o furor da vanguarda modernista, pelo romance de 30, responsável pela projeção de nomes como Raquel de Queiroz, Jorge Amado, José Lins do Rego, Graciliano Ramos, entre outros.

Ainda que com Graciliano Ramos assistíssemos a uma problematização da noção regionalista, a questão só parece ser superada com Guimarães Rosa, normalmente integrado pelas historiografias literárias na terceira geração do Modernismo brasileiro. A participação do volume de contos Sagarana em certame literário de grande alcance nacional arrancou de Graciliano o reconhecimento da promessa que viria a dar seu autor no plano nacional. A aposta no grande romance de Guimarães Rosa não alcançou o outro em vida, como ele mesmo já previra.

Se é verdade que em Rosa a expressão do homem de raízes rurais alcança um estatuto diferenciado, não mais marcado pelo ranço da perspectiva discriminatória ou carnavalizada, também nos parece correto afirmar que ele não deixa de 
representar o outro. Um outro, é verdade, que pode ser tocado pelo sentimento solidário, conforme expresso no conto "Sorôco, sua mãe, sua filha", em que, diante da situação trágico-cômico traduzida pelo embarque simultâneo da mãe e da filha do protagonista para um centro psiquiátrico, ambas alienadas, toda a cidade se põe a cantar a cantiga tartamudeada por elas num surpreendente gesto de solidariedade à solidão de Sorôco. Ainda assim, é justamente a condição de alteridade que torna relevante essa voz que escapa ao previsível. Não há a dissolução de barreiras, mas sim uma empatia momentânea.

É nesse sentido que a linguagem urdida pelo texto faz-se força política, quando consegue apontar uma via de superação diante do impasse estético e ideológico secular, que quase sempre primou por evidenciar as diferenças e a realçar uma suposta superioridade do autor-narrador.

Contudo, não se deve perder de vista que a linguagem que se apresenta nessa parcela da obra rosiana, embora crie no leitor uma impressão de oralidade e de proximidade às culturas populares, é fruto de uma estilização. Conforme pesquisas atestadas por vários linguistas, o discurso do romance é resultado de uma elaboração literária. Se assim não fosse e se tratasse de simples transposição, a leitura da narrativa seria totalmente irrealizável. Como demonstrado, por exemplo, por Terezinha Souto Ward, trata-se de uma fusão de elementos híbridos, tais como recorrência a neologismos, ao léxico regional e também ao erudito, que produzem uma impressão singular no leitor, levando-o a atribuir essa singularidade como expressão do meio em que se dá o enredo. Ou seja, o popular que extravasa no romance está, ao fim e ao cabo, muito mais vincado ao domínio linguístico, a um processo de estilização, que propriamente à verossimilhança ao modelo oral regional. ${ }^{4}$

Também para Alfredo Bosi, a perspectiva ideológica evidenciada na narrativa rosiana é derivada de um recurso linguístico: "A sua narrativa, que parece a tantos ardidamente moderna e até mesmo experimental pela ousadia das soluções

\footnotetext{
4 A pesquisadora vale-se da análise da fonologia, do léxico, da sintaxe e do discurso utilizados no romance a fim de verificar "...como consegue criar a impressão de realismo linguístico selecionando certos aspectos da linguagem oral que estiliza e incorpora à escrita de Grande sertão: Veredas." (WARD, 1984, p. 35). Vários estudos posteriores comprovam essa via, como é o caso da tese de Fabiana Buitor Carelli, Ruína e construção: oralidade e escritura em João Guimarães Rosa e José Luandino Vieira, defendida na USP em 2003, ao demonstrar que "o substrato de oralidade aparentemente presente nesses textos é um efeito criado pela ficção e só existe, portanto, como artefato literário".
} 
formais, realiza, com as artimanhas da linguagem, uma nova tradução do pensamento arcaico-popular" (BOSI, 1988, p. 23).

Não se trata de refutar a inclusão no romance, às vezes de modo bastante intenso, das culturas orais e populares, mas sim de constatar que o processo não se dá por mera transposição; em lugar disso, verifica-se uma intensa reelaboração linguística, ou seja, uma função mediadora que, historicamente, possibilitou a superação literária em termos da tradição regionalista.

De forma aproximada, cremos que defender a representação das culturas populares moçambicanas na obra de Mia Couto tal como um registro fotográfico e afetivo concorreria para um esvaziamento de seu investimento literário, como se não coubesse ao artífice a criação de uma realidade literária. O próprio autor aborda a questão, concluindo pela perda de sentidos ao se eleger um discurso fundado numa ideia de tradição:

Também Moçambique vive a criação de uma razão de Estado, de processos de uniformização linguística e cultural. A negação dessa globalização doméstica é, muitas vezes, feita por via da sacralização daquilo que se chama tradição. África tradicional, África profunda e outras entidades folclorizadas têm sido erguidas do lado de fora e de dentro de África. A tradição surge como uma espécie de lugar congelado da cidadania, uma nação que só vive estando morta. (COUTO, 2011, p. 112).

\section{O médium em Grande sertão: veredas e nos romances de Mia Couto}

Apresentado ao leitor com certo menosprezo, o interlocutor de Grande sertão revela, contudo, sua relevância ao possibilitar a transposição de uma narrativa que não seria audível fora do seu entorno e, de sobretudo, registrá-la num nível escrito, canal que viabilizaria sua difusão para um público letrado. ${ }^{5}$ Nesse sentido, a narrativa toca em questões que se arrastam desde a história colonial,

5 Passagens como “... consoante o senhor escrito apontará..." (ROSA, 2006, p. 467) ou "O senhor escreva no caderno: sete páginas..." (ROSA, 2006, p. 500) atestam a função de escriba do interlocutor de Riobaldo. 
como a da ausência do registro escrito por parte das culturas não letradas em assinalar sua história e, por consequência, a lacuna de suas perspectivas diante dessa mesma história.

A contrapor-se ao interlocutor, o narrador prima em afirmar a sua pouca sabedoria:

O senhor tolere minhas más devassas no contar. É ignorância. Eu não converso com ninguém de fora, quase. Não sei contar direito. Aprendi um pouco foi com o compadre meu Quelemém; mas ele quer saber tudo diverso: quer não é o caso inteirado em si, mas a sobre-coisa, a outra-coisa. Agora, neste dia nosso, com o senhor mesmo - me escutando com devoção assim - é que aos poucos vou indo aprendendo a contar corrigido. (ROSA, 2006, p. 198).

O narrador, segundo ele mesmo detentor de poucos saberes, narra ao escriba misterioso o teor de uma história ainda não assimilada por seu protagonista ocorrida num espaço muito singular: o sertão mineiro. Muito já se estudou a respeito da questão espacial no romance em que o sertão chega mesmo a atingir contornos metafísicos, manifestado em formulações tais como: "O sertão é do tamanho do mundo" (ROSA, 2006, p. 73); "Lugar sertão se divulga: é onde os pastos carecem de fechos" (ROSA, 2006, p. 8), ou "O sertão está em toda a parte" (ROSA, 2006, p. 8), e ainda, "[...] sertão é onde o pensamento da gente se forma mais forte do que o poder do lugar." (ROSA, 2006, p. 25). Essa inscrição além da espacialidade física vai assinalar o lugar da aventura. É aí que se dá o encontro entre culturas que vivem de costas voltadas entre si dentro do mesmo país.

Esse lugar, já por si mesmo especial, guarda ainda dentro dele microespaços que ganham outra conotação mais encantada na narrativa. É o caso do Liso do Suçuarão, um estreito que não era desfiado pela força humana pela inclemência de suas condições naturais, como a ausência de qualquer vegetação e de cursos de água, além de um calor extremo. Na primeira tentativa de romper o cerco, a tropa que Riobaldo integrava padece quase toda à morte. Na segunda vez, após a proteção alcançada mediante o pacto firmado com o diabo, tudo se resolve como num passe de mágica durante os nove dias da travessia. Função semelhante e iniciática desempenham as Veredas Mortas, lugar onde se realiza o pacto, marcado pelo ar sombrio, em que "o espaço é tão calado, que ali passa o sussuro 
de meia-noite às nove horas" (ROSA, 2006, p. 98).

Em Mia Couto verificamos um fenômeno semelhante. O leitor estrangeiro, sedento em vislumbrar a África profunda, em geral descuida dessa demarcação narrativa, identificando a parte pelo todo, ou seja, o espaço da narrativa como uma metáfora das comunidades moçambicanas em geral, mas trata-se de fato de assinalar lugares muito específicos e bastante isolados dentro do próprio país. Exceto o espaço do primeiro romance, Terra sonâmbula, que na sua opção pela estrada significa tanto o ponto esquecido entre mundos em guerra como também a possibilidade de saída desse círculo, os demais romances de Mia Couto editados no Brasil instauram em suas tramas o reino do distante, ou dos confins, para pensarmos numa expressão em termos de mundo literário. ${ }^{6}$

A península, de $A$ varanda de Frangipani, assinala um local somente acessível pelo ar, visto que as minas esquecidas pela guerra colonial impossibilitam que qualquer homem se aproxime pelo continente. Espacialmente perdida, a antiga fortaleza é também espaço de homens e mulheres desprezados pela nova sociedade, funcionando como um asilo para idosos que só se mantém pela dedicação da enfermeira Marta.

A Tinzagara, de $O$ último voo do flamingo, às margens da Estrada Nacional, evidencia a distância dos centros urbanos quando convoca a presença de representantes governamentais para resolver o caso dos soldados da ONU que começam a explodir misteriosamente. Luar-do-Chão, localizada na ilha em que se passa Um rio chamado tempo, uma casa chamda terra, de forma semelhante à fortaleza de $A$ varanda de Frangipani, possui um único acesso, por barco, que, em meio à história, é ainda queimado. A Vila Longe, de $O$ outro pé da sereia, é um mundo perdido em ruínas em que até as antigas casas desfazem-se em pó. Vila Longe e Antigamente, lugar ainda mais ermo que o outro, já assinalam pelos nomes a condição de insulamento a que estão sujeitas. Por sua vez, a Vila Cacimba, do romance Venenos de Deus, remédios do Diabo, se dispersa diante do olhar do viajante pela neblina que a envolve constantemente.

Contudo, cabe a mítica Jesusalém, de Antes de nascer o mundo, a melhor expressão de isolamento humano. Lá vivem no mais ermo dos ermos Silvestre

6 O "reino dos confins", expressão cunhada por V. Propp, designa, nas narrativas maravilhosas estudadas pelo teórico, o local com conotações fantásticas em que se desenvolve a aventura do herói. PROPP, 1997. 
e seus filhos que, influenciados pela história contada pelo pai, acreditam que o mundo acabou e que são eles os últimos exemplares da espécie humana. Inspirando-se ou não em Guimarães Rosa, a realidade aqui alcança também uma dimensão meio onírica, fora dos sentidos humanos. A confissão da Leoa volta a investir na história de uma vila esquecida, Kulumani, com seus moradores em processo de alheamento da realidade política e social de seu país, no momento em que ataques de leões aos habitantes atrai a atenção das autoridades para o vilarejo.

Essa encenação de um espaço de difícil acesso pelas vias geográficas opõe-se claramente à imagem dos centros urbanos do país ou do exterior, para quem os viventes dessas localidades possuem apenas um valor de cifras. Por essa razão, tais representações espaciais não devem ser percebidas apenas como metonímias de Moçambique, visto que elas se prestam a simular nos romance as tensões e os conflitos que perpassam essa multiplicidade de povos e diferentes culturas.

$\mathrm{Na}$ tentativa de traduzir tais confrontos, encontramos a figura do mediador que, nos romances de Mia Couto, assume uma função mais ativa se comparado a Grande sertão, veredas, atuando como personagem e, muitas vezes, como protagonista. Se o menino Muidinga, em Terra sonâmbula, converte a história de Kindju do código escrito para o oral para que Tuahir, seu protetor, possa acompanhar a narração, essa função ganha maior expressão com o inspetor de polícia Izidine Naíta, de $A$ varanda de Franjipani, dividido entre os dois mundos: aquele das tradições orais em que foi criado e o da cultura letrada, no qual se formou e em que se encontra estabelecido no presente.

Em $O$ último voo do flamingo assistimos à presença de um filtro duplo: a do oficial da ONU, Massimo Risi, encarregado de investigar as explosões humanas, e o tradutor, habitante local, que se distingue dos demais por dominar outros códigos linguísticos, e que funcionará como principal narrador do livro. É por meio de sua pena, como em Grande sertão, veredas, que temos acesso à história passada, pela escrita do acontecido, muitos anos depois.

Um rio chamado tempo, uma casa chamada terra traz-nos a figura de Mariano Malta, que retorna à aldeia natal para acompanhar os rituais fúnebres do avô, patriarca de mesmo nome. O neto, após muitos anos estudando fora, já não se reconhece nas tradições culturais, e a narrativa trata justamente desse período de reconciliação. 
Já $O$ outro pé da sereia comporta uma estrutura mais complexa ao se cruzarem dois tempos históricos distintos: o período contemporâneo e o século XVI, através de uma imagem sacra encontrada por Mwadia Malunga, provavelmente pertencente à expedição que Gonçalo da Silveira fizera em 1560, de Goa ao antigo Reino do Monomotapa. Nesse caso, não se pode afirmar ser o choque espacial o responsável pelo desdobrar do enredo, como nos outros romances, até porque a protagonista vive, segundo ela mesma acredita, em companhia do amante que havia sido preterido por sua família numa localidade em que são os únicos habitantes, Antigamente. Desse modo, é por meio do resgate do tempo das navegações e das histórias dos personagens nela envolvidos que se dá o confrontamento; confrontamento figurado, sobretudo na tensão entre duas culturas: a que vê na imagem Kianda, a deusa das águas, e a cristã, que a encara a estátua como representação de Nossa Senhora. Mwadia circula entre esses mundos, o da infância, por meio das memórias, e o do passado colonial, por meio dos documentos encontrados, na tentativa de construir a sua identidade.

Em Venenos de Deus, remédios do Diabo, a mediação cabe a Sidónio Rosa, médico português que chega a Vila Cacimba em busca de Deolinda, com quem se envolvera em Lisboa anos antes. Em lugar dela, Sidónio encontra seus pais, Bartolomeu e Munda, e, na expectativa de que a filha regresse de uma viagem misteriosa, passa a atender gratuitamente no posto de saúde local. A amizade que se estabelece com o casal, e, sobretudo com Bartolomeu guarda, contudo, momentos de de disputa em que vêm à tona os preconceitos raciais reprimidos:

Ficam em silêncio. "Cabrão do preto", pensa o português. E logo se envergonha do pensamento. Raio de lapso racista, como é possível ter pensado uma coisa destas? Talvez seja melhor retirar-se, deixar que o ar fresco lhe esfrie os nervos. Escuta, então, as palavras initeligíveis que o doente rilha entre os dentes.

- Mezungu wa matudzi. [Expressão que significa: "Porcaria de branco"]. (COUTO, 2008, p. 92-93).

A estrutura do romance Antes de nascer o mundo também se mostra um pouco mais complexa por abarcar narrativas tanto de temporalidades diferentes que se cruzam, como também focadas em espaços divergentes. Ainda que a tônica espacial se dê em Jesusalém, um povoado perdido em que vivem quatro almas retiradas do mundo, a narrativa é obrigada a retroceder no tempo para costurar 
a história pretérita dessa família desfeita pela violência e também para resgatar a história do colonizador português, morto anos antes naquele mesmo chão de Jesusalém. O elemento alienígena, nesse caso, é Marta, esposa do colonizador assassinado e que viaja a Moçambique na expectativa de entender os motivos do abandono pelo marido a que teria preterido em favor de Noci, a amante. A amizade que surge entre ela e Mwanito, o filho caçula de Silvestre, o único membro da família a utilizar a escrita, favorece o resgate das pontes daqueles habitantes com o mundo antes perdido.

Finalmente, no romance $A$ confissão da leoa, é o caçador Arcanjo Baleiro quem responde pela função moderadora, ao retornar ao interior do seu país, já próximo à aposentadoria, para caçar o leão responsável por várias mortes na imaginária Kulumani, aldeia localizada no extremo norte do país. Assim como em $O$ último voo do flamingo, essa voz parece duplicar-se na presença de um estrangeiro. Enquanto nesse último verifica-se a figura do relator europeu da ONU, espelhada na presença do tradutor local, no último romance de Mia Couto, a comitiva de Arcanjo é incorporada por Gustavo Regalo, um escritor que busca transformar o sangrento acontecimento em livro. A ignorância desse personagem diante de princípios básicos da vida naquela região concorre para criar alguns efeitos de comicidade, agudizando uma tensão entre ele e o caçador, ou entre o campo e a cidade. No entanto, não se pode reivindicar exatamente uma dicotomia entre eles, uma vez que Arcanjo constitui um elemento híbrido entre os dois mundos; domina a arte de viver no campo, mas dele já se afastou há muito. $\mathrm{O}$ acontecimento constitui assim a oportunidade para retomar o diálogo esquecido e de rever seus conceitos em relação ao próprio passado.

Como contraponto ao escritor Gustavo, e equilibrando a balança, encontramos Mariamar, irmã de uma das vítimas e enamorada de Arcanjo desde o tempo em que, vários anos antes, ele esteve ali numa caçada e salvou a menina de um estupro. Mariamar divide com Arcanjo os diários de narração sobre que se estrutura o romance. Mais uma vez nota-se a preocupação do autor em instaurar, por meio da forma, uma polifonia narrativa, visto que não há fato sem que haja sobre ele uma diversidade de olhares que o compõem de forma multifacetada. Enquanto Gustavo vai ao encontro da África "profunda", Mariamar anseia pelo momento em dali sair e deixar para trás a falta de perspectivas a que estão relegadas as mulheres do seu povo. Mariamar também experimentou um percurso fora dos muros de Kulumani, quando educada pela escola da Missão na frontei- 
ra do país vizinho. Se a travessia geográfica é feita por Arcanjo e Gustavo, é, sobretudo Miramar quem a coloca na escrita, desafiando os conselhos do falecido avô: “- Cuidado, minha neta. Escrever é perigosa vaidade. Dá medo aos outros..." (COUTO, 2012, p. 88).

Quase nunca testemunhamos a existência de apenas um personagem mediador. Ainda que a perspectiva algumas vezes incorra mais sobre um deles que instaura uma espécie de périplo entre um possível "centro" conotado com os valores ocidentais e um espaço além do periférico, a obra romanesca de Mia Couto procura deliberadamente enfatizar não especificamente a existência de comunidades remanescentes e quase intactas às influências ocidentalizantes, mas em especial as intrincadas situações de diálogo entre elas e o resto do mundo, através de personagens que, em maior ou em menor grau, revelam esse desconhecimento acerca do outro. Tal enfrentamento é dinamizado pela figura do médium, o que Couto parece perceber na artesania de Guimarães Rosa:

O que Rosa instaura é o narrador como mediador de mundos. Riobaldo é uma espécie de contrabandista entre a cultura urbana e letrada e a cultura sertaneja e oral. Esse é o desafio que enfrenta não apenas o Brasil, mas também Moçambique. Mais que um ponto de charneira necessita-se hoje de um médium, alguém que usa poderes que não provêm da ciência nem da técnica para colocar esses universos em conexão. Necessita-se da ligação com aquilo que João Guimarães Rosa chama de "os do lado de lá". Esse lado está dentro de cada um de nós. Esse lado de lá é, numa palavra, a oralidade. (COUTO, 2011, p. 113).

Nesse sentido, poderíamos afirmar que a experiência desses narradores equivale, através de uma relação de espelhamento, à função delegada a si mesmos por seus autores. Ou seja, os personagens romanescos revelam-se, em certa medida, alter-egos de Guimarães Rosa e Mia Couto. Curiosamente, nota-se nesses autores um perfil profissional semelhante, na área da saúde, ${ }^{7}$ e que sempre

\footnotetext{
7 Guimarães Rosa, formado em Medicina, aprende em suas andanças no ofício pelo interior das Gerais que o viu nascer o mundo do sertanejo, colhido nas páginas de suas inseparáveis cadernetas. Mia Couto, que também desejou enveredar pelos caminhos da Medicina, forma-se, após um turbulento período em que exerceu a função de jornalista, em Biologia, ramo em que atua até hoje como empresário e consultor. A sua biografia, assim como Rosa, também revela em muitas passagens o consórcio entre a prática profissional e o ofício da escrita.
} 
evidenciaram uma atenção bastante especial aos apelos de realidades com que travaram contato. Essa simpatia, ou compaixão, conforme classificado por alguns críticos rosianos, não exime, no entanto, uma tomada crítica frente a essas mesmas comunidades. Se o "sertão" se reveste de sentidos superlativos na fórmula "ser-tão", ele também assinala o lugar do demo, das perversidades e das infelicidades: "Sertão é o penal, criminal. Sertão é onde homem tem de ter a dura nuca e mão quadrada" (ROSA, 2006, p. 110).

Também em Mia Couto, não escapam as críticas a situações que, do ponto de vista das políticas culturais contemporâneas, evidenciam-se repreensíveis e até vexatórias, como é o caso da discussão de gênero sempre presente nos textos coutianos. A mulher e a criança normalmente aparecem como seres especiais nessas narrativas, invertendo uma lógica social a elas atribuída, e a denúncia de práticas, tais como os estupros e as mutilações femininas, mostram-se frequentes. Também a política administrativa faz-se alvo constante da ficcão do autor, reivindicando o olhar dos recursos públicos para as populações abandonadas a sua própria sorte, como assinalado na voz de um de seus personagens: "- Querem saber como morremos? Mas nunca ninguém veio saber como vivemos." (COUTO, 2012, p. 108).

\section{Considerações finais}

É lícito nos questionar por que razão a presença do mediador nos romances de Rosa e Couto ausenta-se nas narrativas mais curtas, formato em que ambos escritores demonstram grande domínio e perícia. Sem a pretensão de uma afirmação taxativa, poderíamos concluir que o gênero romanesco permite uma arquitetura mais ousada, conforme preconizado por M. Bakhtin, pela sua capacidade de articular todos os demais gêneros (BAKHTIN, 2010), enquanto o conto estaria mais limitado a um único fio narrativo.

Além disso, se entendemos o romance como a grande conquista burguesa literária, pode-se aventar a hipótese de que, para romper com o princípio naturalista que deu as bases e que suportou o gênero ao longo de dois séculos, ou seja, o realismo formal, ${ }^{8}$ é necessário investir contra a sua montagem num exer-

8 WATT, 1990. 
cício interno que desafie esses mesmos princípios. A presença de mediadores, assim como a inserção metaficcional possibilitada por esses personagens, funciona como uma rasura em relação à tradição ocidental romanesca, responsável por endossar um discurso que lhe era próprio. A fim de apresentar as outras faces de leitura, a literatura se vê obrigada a transmudar seus próprios artifícios literários. Nessa tradição secular que possibilitou que o outro fosse lido como o mesmo, através do processo de identificação criado pelo gênero, esses autores constroem também o caminho inverso: o do mesmo que se revela outro, contando, entre outros artifícios, com a inclusão do elemento mágico.

Nessa mise en scène, o que sobressai é a própria dificuldade da literatura ao lidar e dar voz às tradições que se mantiveram distanciadas do cânone. Essa presença das tradições arcaicas revela a tensão na sua representação, de forma semelhante ao que prevalece com a sua inclusão no mundo letrado. Assim, a figura do mediador, além de tentar traduzir um mundo irrefratável ao sujeito centrado no espaço urbano e de ter de cumprir essa tarefa por meio do código escrito, parece expressar o drama histórico dessa mesma passagem, a fim de que tais culturas ganhem visibilidade num mundo que as suprimiu.

Em Grande sertão: veredas, assumem-se dois tipos de filtros para que o discurso do sertanejo ganhe contornos de lisibilidade: o filtro do interlocutor e também o do próprio Riobaldo, muitos anos depois dos acontecimentos narrados, que, apesar de permanecer no sertão, já deixou para trás os dias de jagunçagem, tendo se tornado latifundiário, sobrevivendo da cultura da cana e do algodão e da criação animal (ROSA, 2006, p. 166):

Ah, mas falo falso. O senhor sente? Desmente? Eu desminto. Contar é muito, muito dificultoso. Não pelos anos que já se passaram. Mas pela astúcia que têm certas coisas passadas - de fazer balancê, de se remexerem dos lugares. O que eu falei foi exato? Foi. Mas teria sido? Agora, acho que nem não. São tantas horas de pessoas, tantas coisas me tantos tempos, tudo miúdo recruzado." (ROSA, 2006, p. 184).

Narrar é também para Riobaldo um modo de articular o acontecido e de dar-lhe um sentido: "Mesmo o que estou contando, depois é que eu pude reunir relembrado e verdadeiramente entendido..." (ROSA, 2006, p. 138). De forma semelhante, Mia Couto expressa a dilaceração que o invade diante da experiência diaspórica a que esteve sujeito e o significado que a escrita adquire nesse 
contexto:

E eu cresci nesse ambiente de mestiçagem, escutando os velhos contadores de histórias. Eles me traziam o encantamento de um momento sagrado [...]

Por aquela razão, aquele momento agia em mim de maneira contraditória: por um lado, me aconchegava, por outro me excluía. Eu não podia partilhar por inteiro daquela conversa entre deuses e homens. Porque eu estava já carregado de Europa, minha alma já bebera de um pensamento. E os meus mortos residiam num outro chão, longíquo e inacessível. (COUTO, 2011, p. 117).

Ao escolherem como objetos de suas representações povos e culturas longíquas e esquecidas, o romance de Rosa e aqueles de Couto simulam uma tensão de base dessas literaturas desde os tempos coloniais: a ausência da voz daqueles que foram espoliados pelo poder. Em razão disso, os romances não encenam apenas sujeitos e modos de vida singulares diante do poder "civilizador", mas abordam sobretudo a dificuldade e a quase impossibilidade dessa fala ser ouvida sem a tradução de um mediador que, ainda que empenhado, nunca pertenceu ou há muito já abandonou aquele mundo quimérico. 


\section{Referências}

BAKHTIN, Mikhail. "Questões de literatura e de estética". In: A teoria do romance. 6.ed. São Paulo: Hucitec, 2010.

BRAÚNA, José Dércio. O sertão brasileiro na savana moçambicana: apontamentos sobre uma travessia. Revista Sertões. Mossoró-RN, v. 1, n. 1, p. 49-68, jan./jun. 2011. Disponível em: <http://periodicos.uern.br/index.php/sertoes/article/viewFile/112/93>. Acesso em: 14-04-2014.

CARELLI, Fabiana Buitor. Ruína e construção: oralidade e escritura em João Guimarães Rosa e José Luandino Vieira. Tese de doutorado. São Paulo: USP, 2003.

CHAVES, Rita. Guimarães Rosa: do sertão às savanas. Revista Ângulo, Lorena-SP, n. 115, out./dez., 2008, p. 136-143.

COUTO, Mia. Um rio chamado tempo, uma casa chamada terra. São Paulo: Companhia das Letras, 2003.

. O último voo do flamingo. São Paulo: Companhia das Letras, 2005. . O outro pé da sereia. São Paulo: Companhia das Letras, 2006. . A varanda do frangipani. São Paulo: Companhia das Letras, 2007. . Venenos de Deus, remédios do diabo. São Paulo: Companhia das Letras,

2008.

. Antes de nascer o mundo. São Paulo: Companhia das Letras, 2009.

E se Obama fosse africano?: e outras intervenções. São Paulo: Companhia das Letras, 2011. . A confissão da Leoa. São Paulo: Companhia das Letras, 2012.

FONSECA, Maria Nazareth Soares; CURY, Maria Zilda Ferreira. Mia Couto: espaços ficcionais. Belo Horizonte: Autêntica, 2008.

MACÊDO, Tania. Angola e Brasil: estudos comparativos. São Paulo: Arte \& Ciência, 2003. PROPP, V. As raízes históricas do conto maravilhoso. São Paulo: Martins Fontes, 1997. ROSA, Guimarães. Primeiras estórias. Rio de Janeiro: Nova Fronteira, 1988. . Grande sertão: veredas. Rio de Janeiro: Nova Fronteira, 2006.

ROSENFIELD, Katrhrin H. "A matriz formal do romance". In: Desenveredando Rosa. A obra de J. G. Rosa e outros ensaios rosianos. Rio de Janeiro: Topbooks, 2006.

SILVA, Ana Cláudia da. O rio e a casa: imagens do tempo na ficção de Mia Couto. São Paulo: Cultura Acadêmica, 2010.

WARD, Terezinha Souto. O discurso oral em Grande sertão: veredas. São Paulo: Duas Cidades: Instituto Nacional do Livro, 1984.

WATT, Ian. A ascensão do romance. São Paulo: Companhia das Letras, 1990. 